\title{
ESTUDIOS
}

\section{Repensando la hipótesis del innatismo: genes y lenguaje ${ }^{1}$}

\author{
Raymundo Casas Navarro \\ Universidad Nacional Mayor de San Marcos \\ casasnavarro1@hotmail.com
}

Everything should be as simple as posible, but not simpler.

Albert Einstein

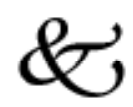

\begin{abstract}
Resumen
Desde la segunda mitad del siglo XX se configuró un movimiento científico que clamaba por una mayor colaboración entre la lingüística y la biología, y el término Biolinguística comenzó a fraguar un nuevo horizonte interdisciplinario que tenía un preclaro objetivo: estudiar el lenguaje como un fenómeno eminentemente natural.

Dado que en la última década del siglo XX hubo la concurrencia de dos avenidas científicas impactantes (los estudios sobre el cerebro con nuevas técnicas muy poderosas y la irrupción del programa minimalista en la teoría linguiística), el sueño del proyecto de la biolingüística comenzó a cristalizarse y en el nuevo milenio ha tenido unos prolegómenos bastante promisorios: la fundación de una revista especializada, la publicación de manuales actualizados y el trayecto serio de programas de doctorado.

En este marco interdisciplinario, surge la necesidad de replantear la cuestión del innatismo asociado al dispositivo de adquisición del len-
\end{abstract}

1 El presente artículo es el resultado del proyecto de investigación (110302191) desarrollado en el Instituto de Investigaciones Linguiísticas (INVEL) en el marco de los proyectos de investigación 2011 de la Universidad Nacional Mayor de San Marcos. 
guaje (o la denominada gramática universal). Una respuesta sugerente puede provenir del análisis desprejuiciado de la relación entre genes y lenguaje. El engarce entre el genotipo lingüístico (la gramática universal) y el fenotipo linguístico concebido como un proceso madurativo (con algunos aspectos de epigénesis) entraña hacer una reconsideración sobre el innatismo, postulado raigal de la tradición generativa.

La comprensión de las bases ontogenéticas y filogenéticas del lenguaje nos conduce a sostener la siguiente hipótesis: en la forja de la gramática universal ha intervenido el mecanismo conocido como efecto Baldwin, lo que cabe interpretar, como señalan Calvin y Bickerton, dentro del marco evolutivo más ortodoxo. Asimismo, el programa biolingüístico entraña hacer una reducción definitoria del lenguaje: este se conceptúa stricto sensu, siguiendo el criterio sintactocéntrico, como un mecanismo de fusión (Merge) y recursión. Así se puede concluir que el lenguaje está genéticamente determinado, no como una metáfora sugerente, sino como un constructo teórico bien cimentado.

Palabras claves: Gramática universal, biolinguística, genotipo, innatismo.

\begin{abstract}
In an interdisciplinary framework (studies on the brain with powerful new techniques and the emergence of the minimalist program in linguistic theory), it's necessary to rethink the question of innateness associated with language acquisition device (or the so-called universal grammar). A response may come from the analysis suggestive unbiased of the relationship between genes and language. The linker between genotype language (universal grammar) and linguistic phenotype conceived as a maturation process (with some aspects of epigenesis) involves making a reconsideration of innateness.

Understanding ontogenetic and phylogenetic basis of language leads us to support the following hypothesis: in the emergence of universal grammar has intervened mechanism known as the Baldwin effect, which can be interpreted within the evolutionary framework more orthodox. The Biolinguistics also involves making a reduction defining language: this is conceptualized, strictly speaking, following the criterion sintactocentric as merge and recursion. So we can conclude that language is genetically determined, not as a suggestive metaphor, but as a wellgrounded theoretical construct.
\end{abstract}

Keywords: Universal grammar, Biolinguistics, Genotype, Innateness. 


\section{Introducción}

Desde que se formuló en la década de 1950, la gramática generativa se comprometió en un framework innatista que, sobre la base del argumento de la pobreza del estímulo, propugnó una visión endógena del desarrollo del lenguaje en contra de los enfoques conductistas dominantes en ese entonces. Así se postuló un mecanismo de adquisición del lenguaje genéticamente determinado y se apostó por conformar una nueva disciplina, bautizada tempranamente como Biolinguiística, que se involucrara seriamente en el estudio de los fundamentos biológicos del lenguaje (Lenneberg 1967). Si bien tal empresa se logró consolidar, la argumentación innatista fue eminentemente psicolinguiística y quedó como una deuda pendiente el apuntalamiento biológico del programa. De manera progresiva se puede decir que los trabajos intentaron consolidar una suerte de triple entente en la visión generativa (la hipótesis del innatismo, el axioma de la gramática universal y el corolario de la especificidad del dominio linguiístico). En el volumen editado por Gopnik (1997) se blanden argumentos de impacto: por ejemplo, a pesar de que los inuit han decidido culturalmente no hablarles a sus infantes, estos ostentan un desarrollo normal del lenguaje.

En la década de 1990, con la irrupción del programa minimalista (un cambio altamente progresivo, si no revolucionario, en la línea del modelo de Principios y Parámetros), se logró fortalecer el leitmotiv inicial acerca de los estudios en la ontogenia y filogenia del lenguaje. De modo paralelo, los vertiginosos avances en las ciencias del cerebro (con métodos sofisticados como la tecnología de emisión positrónica y enfoques audaces sobre mecanismos epigenéticos en la nueva dimensión del programa evo-devo) dieron una nueva imagen sobre la biología de la cognición con profundas implicancias sobre la modularidad, la base innata del lenguaje, la ontogenia y la filogenia del lenguaje. De modo progresivo, pero con notable avance teórico, se ha llegado al corolario de que, como lo expresó Noam Chomsky en The San Sebastián Meeting (2006), estamos en condiciones de ir más allá de la especulación: ya se pueden poner los cimientos de una imagen científicamente solvente sobre la naturaleza y función del órgano del lenguaje.

Resulta interesante constatar que el giro biolinguístico es heteróclito y hasta proteico. Además del clásico trabajo de Lenneberg, se han publicado ensayos diferentes como los de Deacon (1997), Jenkins (2000), Givón (2002), Lieberman (2006), Hurford (2007), entre otros. Igualmente interesante es constatar que, a diferencia de algunas décadas, los trabajos de iniciación linguiística no pueden soslayar el aspecto evolutivo y, más bien, se sumergen en la cuestión de la evolución de la gramática: Pinker (1994) y Jackendoff (2002). 
El programa minimalista (Chomsky 1995, 2002) plantea que la elucidación de la naturaleza de la facultad del lenguaje implica que la teoría linguiística se constriña de una manera tan fuerte como nunca se hizo en la historia de la linguística (ni siquiera el riguroso formalismo de Hjelmslev osó hacer algo siquiera parecido).

Así ha surgido en este nuevo milenio un nuevo programa científico, de vertiente interdisciplinaria, conocido como la revolución biolinguiística cuyo objetivo perspicuo es sentar las bases científicas para comprender la capacidad humana para adquirir y usar el lenguaje. En la medida en que esta nueva disciplina se enmarca en la esfera de la ciencia natural, el nuevo enfoque se orienta a postular los mecanismos restrictivos de la cognición que posibilitaron la aparición del lenguaje en nuestra evolución y la emergencia del lenguaje en un periodo relativamente corto de maduración.

La biolinguíística como tal es una empresa promisoria que ya cuenta con una revista de alto nivel (Biolinguistics ISSN 1450-3417) y programas de posgrado en universidades de prestigio. En los últimos tiempos, mucho se ha debatido sobre la relación entre genes y lenguaje con el protagonismo mediático del gen FOXP2 involucrado en el trastorno específico del lenguaje (un desorden gramatical con bases hereditarias). El modelo clásico del generativismo (P\&P) predecía una determinación genética directa y, por ello, se vio como una corroboración crucial el descubrimiento de genes involucrados en la modularidad de la gramática. Sin embargo, el programa minimalista (PM), enmarcado en la nueva perspectiva de la biología evolutiva del desarrollo (evo-devo), predice, más bien, que un órgano tan complejo como el lenguaje debe involucrar procedimientos epigenéticos y sería muy improbable que esté determinado solo por un gen. Se podría postular la interacción de muchos genes (la cantidad se determinará en virtud de la investigación fáctica pertinente) en la ontogenia del lenguaje, según el espíritu del aserto esencial de Gary Marcus (2004): Genes build neural structures, not behavior.

En la medida en que el puesto que ocupa el hombre en el cosmos está determinado fundamentalmente por el lenguaje y en virtud de que nada se puede saber sobre el lenguaje si no es en el marco de la biología de la gramática (parafraseando al gran Dobzhansky), el estudio del engarce entre genes y lenguaje se presenta como trascendente y de valor ecuménico. El emergente programa biolinguiístico tiene un impacto científico insoslayable en tanto que permitirá construir una imagen solvente sobre la naturaleza humana y, asimismo, podrá aclarar suficientemente los cimientos biológicos de la comunicación humana en lo que esta tiene de específico.

Tal como es entendido por los editores de Biolinguistics (Boeckx \& Grohmann 2007), este nuevo framework se puede entender en dos sentidos, uno débil y 
otro fuerte. En el sentido débil, la biolinguiística se encargaría de estudiar las propiedades de la gramática en el marco de hipótesis universales de índole formal. En el sentido fuerte, se intentaría dilucidar los engarces entre la teoría linguística formal y disciplinas sustantivas como la genética o la biología evolutiva.

Estamos de acuerdo con la actitud expresada en el manifiesto de los editores de la revista Biolingüística:

We are fully aware of the fact that the uniquely interdisciplinary character of biolinguistics poses difficult problems of communication and misunderstandings, but we feel that a growing community of scientists of diverse background, including linguists, evolutionary biologists, molecular biologists, neuroscientists, anthropologists, psychologists, computer scientists, (language or speech and hearing) pathologists, and so on, are slowly overcoming these challenges. Only collaboration and mutual respect will make this type of research possible. We would be delighted if the contributions to Biolinguistics could clarify issues, unearth new data, and answer some of the questions that will help us understand the nature of language, and what it is that makes us human. (Boeckx \& Grohmann 2007: 3)

De acuerdo con una epistemología racional y ponderada, requerimos hallar evidencias externas para propugnar la plausibilidad del innatismo. Los argumentos tradicionales cartesianos o de la corriente psicolinguística (por ejemplo, la refutación del enfoque conductista del aprendizaje) no son suficientes. Por ello, el PM (Longa \& Lorenzo 2008) establece que la facultad del lenguaje entraña una esencial bifurcación entre aspectos genéticos (codificados en la información genética, en el genotipo linguiístico) y procesos epigenéticos que podrían dar cuenta de la información paramétrica (el denominado fenotipo linguiístico). Solo de ese modo se podrá formular o reformular la hipótesis del innatismo que esté a la altura de los tiempos y, en especial, va a consistir en una revisión de la novísima biología evolutiva del desarrollo (evo-devo), dado que este reciente framework entraña una investigación que se configura más allá de la primacía de los genes (Carroll 2005). De ahí el corolario inevitable de que los genes no marcan el punto final en la investigación del lenguaje.

Sin embargo, no creemos que la actitud apriorística de negar la acción de genes específicos en el juego del lenguaje [Calvin \& Bickerton (2000) o Changeux (2002)] configure un argumento de principio inexpugnable, porque, finalmente, todo puede pasar en un terreno en el que todavía falta desbrozar mucho el camino. En particular, aún se tiene que dilucidar convenientemente qué es lo que llamamos lenguaje, dado que las concepciones académicas difieren mucho (verbigracia, las tradiciones saussuriana, bloomfieldiana, griceana, chomskiana, langackeriana, etc.), y ni que decir de la intuición del hombre de a pie (lo que se puede denominar teoría linguiística popular). Por cierto, actual- 
mente, se impone un escepticismo morigerado como el de Jackendoff (2002), aunque sin apostar por un tiempo como él lo hace:

It is certain that the genes cannot directly code a set of functional principles. All they can do is code the synthesis of proteins under particular environmental circumstances, which in turn guide certain unknown parameters of brain growth. [...] I think it fair to say the manner in which this process is guided by genetics or anything else is pretty much a mystery at the momento. [...] So at the momento I think there is really no hope of understanding in any detail the wonderfully indirect mechanisms for genetic transmission of Universal Grammar. In fifty years, perhaps... (Jackendoff 2002: 90).

En relación a la definición del lenguaje, en nuestra década se ha dado una polémica de altos ribetes teóricos y los puntos más disputados han sido el lugar que ocupa el lenguaje en la mente y su evolución como facultad humana específica y estricta. Para orillar siquiera una respuesta fundada hay que sumergirse en ese fascinante debate en el que el mismo Chomsky ha participado con entusiasmo: Hauser et alii (2002), Pinker \& Jackendoff (2005), Fitch et alii (2005) y Jackendoff \& Pinker (2005). El quid del asunto recae sobre la recursividad, propiedad que nos parece esencial para una definición formal del lenguaje. Inclusive, Everett (2005) ha presentado un caso que enciende aún más la hoguera: una lengua natural amazónica, la lengua pirahã, carecería de recursividad. Este último punto nos lleva a considerar que estamos ante un problema peliagudo y, por ello, trascendental.

\section{Marco teórico de la investigación}

Sobre el eterno y espinoso problema de la definición del lenguaje, nuestro punto de vista es que no se puede avanzar nada si no se hace una labor de aclaración, una suerte de reconstrucción racional para quedarnos con lo que, a nuestro juicio, puede considerarse esencial desde el punto de vista científico. En ese sentido, la ciencia del lenguaje (la intuición viene ya de la glosemática de Hjelmslev 1943) puede trabajar ventajosamente (esto es, aplicando los más elevados criterios de la racionalidad científica) si se atiene a la realidad formal del lenguaje.

Con esta abstracción (que implica dejar de lado aspectos muy importantes ligados con el lenguaje humano), se puede considerar que la mejor definición del lenguaje está ligada a una perspectiva sintactocéntrica: el lenguaje en sentido estricto es suma mínima de características asociadas con la operación de fusión o ensamble (merge) y la recursividad.

Nuestro estudio apuesta científicamente por entender que la recursividad y el ensamble nos brindan la definición de la gramática universal y, de ese modo, 
configuran la noción de genotipo linguiístico, de tal manera que el vínculo entre genes y lenguaje se reduce a esa abstracción, y debe discutirse solamente en esos términos.

Situado así el panorama, el asunto consiste en tratar de distinguir si un gen o un conjunto de genes trabajan mancomunadamente para producir el lenguaje en sentido estricto. En buena cuenta, se trata de establecer una correlación entre la configuración neuronal del cerebro (o áreas del cerebro) y la manera como los niños humanos desarrollan el sistema recursivo que define su gramática mental.

El trabajo experimental hasta ahora ha tenido que ver con los análisis de las afasias y disfasias. No obstante, hasta ahora no contamos con una prolija antología del habla defectuosa (como añoran Calvin \& Bickerton 2000). La correlación entre los genes candidatos y las propiedades gramaticales nos dará luces esplendentes al respecto. Por ejemplo, como plantean Poeppel \& Embick (2005), las novísimas técnicas de imagenología cerebral podrán iluminar aspectos de la computación linguiística: así una tarea linguiística con el uso de verbos se podrá correlacionar con el incremento de la actividad cerebral en una región específica (Sahin et alii, 2009). Resulta poco probable hallar otro tipo de correlaciones más sustantivas.

La gramática universal $(\mathrm{GU})$ es la base innata a partir de la cual los niños adquieren su gramática particular (GP) en un proceso de maduración motivado fuertemente por factores endógenos. La nueva visión minimista de raigambre chomskiana considera que el lenguaje está constituido por un lexicón (provisto de entradas con rasgos fonológicos, morfosintácticos y semánticos) y un sistema computacional empleado para la construcción de oraciones. El sistema computacional es una sintaxis estricta en la que operan un conjunto de restricciones sobre los procesos gramaticales (cuyo control está dado por consideraciones perceptivas en la forma fonética, FF, o por consideraciones conceptuales en la forma lógica, FL). La sintaxis minimalista es óptima en la medida en que la relación entre sonidos y significados se da cuenta con simplicidad, naturalidad, simetría, exactitud y economía. Ahora bien, la condición óptima se inscribe en el marco biológico de la adaptación, razón por la cual el programa minimalista entraña un auténtico giro biolinguiístico.

Por ejemplo, la economía se vincula con una reducción drástica en la explicación de las diferencias paramétricas entre lenguas. Así, por ejemplo como postula Pollock en su seminal trabajo (1989: 365):

I will in fact show that [a few sistematic differences between French and English] can be deduced from the structure of Universal Grammar (UG) and one abstract parameter having to do with what I will call the "opacity" or "transparency" of Agreement in French and Modern English. 
Así, si consideramos los siguientes enunciados, podemos entender el razonamiento ya clásico de Pollock:

(a) John often kisses Mary.

(a') * John kisses often Mary.

(b) Jean embrasse souvent Marie.

(b') * Jean souvent embrasse Marie.

En francés, se da un movimiento visible del verbo a una posición abstracta para verificar la concordancia sujeto-verbo. En inglés, el movimiento es encubierto (solo ocurre en la FL). ¿Por qué en francés el movimiento es visible y en inglés el movimiento es encubierto? Debido a que los rasgos verbales del francés son fuertes y los rasgos verbales del inglés son débiles. En consecuencia, una diferencia paramétrica (rasgo fuerte versus rasgo débil) da cuenta del fenómeno de la posición preverbal del adverbio en inglés. Ahora bien, no se trata de una explicación ad hoc, por cuanto se puede aplicar, por ejemplo, a la diferencia del futuro en inglés (rasgo débil) y el castellano (rasgo fuerte como el francés):

(c) Mary will dance.

(d) María bailará.

Nuevamente, en castellano se da un movimiento visible por el cual el verbo alcanza una posición abstracta para la concordancia. En inglés, debido al rasgo débil del verbo, no se da un movimiento visible, sino uno encubierto (covert).

La recursividad se puede definir formalmente con la siguiente fórmula:

$(\alpha) X \rightarrow \ldots . . . . .$.

Así, en cualquier lengua natural, es posible operar fácilmente con las siguientes expansiones, sin necesidad de ser un artista literario como Raymond Queneau:

María no dijo nada.

María dijo que Rosa no dijo nada.

María dijo que Rosa dijo que Claudia no dijo nada.

María dijo que Rosa dijo que Claudia dijo que Sofía no dijo nada.

La recursividad entraña una aplicación cíclica con una propensión al infinito. Pues bien, se puede barruntar un gen o un conjunto de genes que conspiran para la aplicación recursiva como propiedad de la GU. En este sentido, la recursividad se puede entender como una proyección a partir del lenguaje del pensamiento (el mentalés) que debe estar asentado en el genotipo humano universal (Smith \& Law 2007; Fodor 2008).

En el clásico trabajo de Mehler \& Dupoux (1990), se hace un eximio epítome de los principales argumentos a favor de la hipótesis del innatismo linguiístico y se arriba a la conclusión de que el lenguaje se encuentra asentado sobre disposiciones específicas e inherentes al cerebro humano que se transmiten genéti- 
camente. El mecanismo de "aprendizaje por olvido» que ellos señalan conduce inexorablemente a conferir plausibilidad a la hipótesis del innatismo linguiístico.

Como ejemplificación presentaremos algunas evidencias cimentadas en la literatura especializada:

(a) Un bebé francés puede categorizar todos los sonidos de todas las lenguas. Por ejemplo, distingue entre los sonidos $[\mathrm{p}]$ y $\left[\mathrm{p}^{\mathrm{h}}\right]$. Ahora bien, en francés la diferencia no es distintiva, pero sí en hindi: $/ \mathrm{p} / \mathrm{y} / \mathrm{p}^{\mathrm{h}} \%$. Un bebé japonés distingue muy bien entre $[\mathrm{r}]$ y [l], pero a los adultos japoneses les resulta muy difícil hacer esa distinción. Los bebés, en consecuencia, están más dotados que los adultos: la adquisición de una lengua consiste en una pérdida parcial que se traduce en la fijación de un parámetro. Los bebés comienzan a perder su capacidad discriminatoria superlativa a partir de los doce meses y no se trata de una pérdida sensorial, sino funcional: los bebés olvidan las distinciones que «compiten» con las de su lengua materna. De esto se deriva que el estado inicial del lenguaje es muy rico y se puede postular una fuerte base innata. Todas las lenguas pueden ser adquiridas por cualquier niño. Si cualquier bebé humano es capaz de adquirir cualquier lengua, entonces las lenguas deben ser, en aspectos profundos y verdaderamente importantes, similares. No todos los niños son capaces de dominar el álgebra, jugar magistralmente el ajedrez o ser expertos dominadores de balón, pero sí todos son expertos hablantes (Bahrick 1988; Cutler et alii 1983).

(b) Los niños que nacen con agenesia del cuerpo calloso no evidencian problemas graves de lenguaje. El desarrollo sintáctico de un niño que llegó al mundo sin cuerpo calloso fue similar al de los niños de su edad (hecho que sugiere que la competencia sintáctica no requiere de comunicación de los hemisferios). Lo que sí se observó es serias lagunas en su conocimiento enciclopédico. Como plantea el generativismo, hay una diferencia fundamental entre el lexicón y el sistema computacional llamado GEN (Barkovich et alii 2001).

(c) El caso de Christopher, el sabio políglota, corrobora que el lenguaje como facultad estricta es un módulo muy específico. El joven tenía una extraordinaria capacidad para aprender nuevas lenguas, pero era incapaz de abotonarse la camisa (Smith \& Tsimpli 1995).

(d) Una familia sufre una anomalía lingüística hereditaria que se transmite de generación en generación sin importar el sexo del individuo. Los miembros de la familia que sufren este trastorno no tienen serios problemas con respecto al vocabulario y sus habilidades no verbales son normales. ¿Cuáles son sus problemas? Presentan fallas en la formación de los plurales, con los tiempos verbales, el género y el aspecto (rasgos 
morfológicos abstractos). Se ha intentado explicar el síndrome específico del lenguaje sobre la base de una hipótesis cognitiva, pero ha sido una vía tortuosa y, por ahora, es inconducente. Cuando se ha analizado a un niño que sufre el trastorno específico del lenguaje (Specific Language Impairment en inglés) se ha detectado que tiene una inteligencia superior a la media, pero muestra una incapacidad sistemática para manipular aspectos de la sintaxis como la recursividad, el marcado de tiempos verbales, la distinción entre pronombres y reflexivos (ComtiRamsden, Botting \& Faragher 2001).

En este nuevo marco interdisciplinario, la confluencia de dos vertientes es necesaria. Por un lado, se trata de apuntalar aún más la sintaxis minimalista y por ello se necesita un trabajo más fino en la recursividad y en la operación del merge (ensamble). Así hay que reducir los primitivos del sistema computacional para quedarnos con los estrictamente necesarios como la localidad, la dependencia estructural, la diferencia entre agente y paciente, etc. Asimismo, profundizar en los aspectos neurales de la biología del cerebro, el auténtico Rubicón entre la comunicación animal y el lenguaje humano. Por ejemplo, se puede constatar que lo que impide hablar a los chimpancés y otros animales no radica en el tracto vocal, sino reside en la configuración cerebral (Knörnschild et alii 2009). Todo ello está enmarcado en el desarrollo del programa minimalista en la medida en que conduce al giro biolinguiístico (Boeckx \& Grohmann 2002: 3):

At the heart of the minimalist program is the question of how much of the architecture of the language faculty can be given a principled explanation. Specifically, minimalism asks how well the engine of language meets design requirements imposed by the cognitive systems it subserves. Inevitably, linguists working in the context of the minimalist programare forced to address and sharpen questions of cognitive specificity, ontogeny, phylogeny, and so on, to even begin to understand the design requirements imposed on the language faculty. This is not to say that previous generations of linguists were not interested in such issues. But in practice biolinguistic issues had little effect on empirical inquiry into questions of descriptive and explanatory adequacy.

Sin embargo, las cuestiones fácticas y los desarrollos teóricos nos obligan a establecer con cautela que el genotipo linguístico tiene cierta flexibilidad (Kirschner \& Gerhart 2005), lo que podría vincularse con los procedimientos de la epigénesis, esto es, la estrecha interacción entre la información del programa de desarrollo y la información que se asimila del entorno. Algunos han sugerido que esto podría revivir las viejas ideas de Waddington (1957) tal como soñó Piaget (Piaget, Chomsky et alii 1983), pero nosotros nos inclinamos por retrotraernos más en el tiempo para invocar el efecto Baldwin en la filogenia del lenguaje: la herencia prevé la transformación de su propia maquinaria (Baldwin 1896). 
De acuerdo con Chomsky (2005), hay tres factores en el diseño del lenguaje: la gramática universal, el entorno de experiencias y los principios biofísicos generales. En nuestra perspectiva, solo el primero apunta a la definición mínima del lenguaje y, en consecuencia, solamente en ese punto se debe plantear la cuestión del innatismo linguiístico.

En lo que sigue, plantearemos las principales hipótesis que han marcado la pauta de nuestra investigación:

Hipótesis 1: El dispositivo innato de adquisición del lenguaje (entendido como ensamble y recursión) expresa el genotipo linguístico, en cierta proporción, autónomo respecto de las experiencias ontogenéticas y mecanismos epigenéticos. Sin embargo, la ontogenia ya no se puede entender como solo un efecto desencadenante del órgano linguíístico.

Hipótesis 2: La simetría entre genes y estructuras neurofisiológicas es suficiente para dar cuenta de la relación entre la gramática universal y la configuración neural del cerebro, pero no basta para explicar el funcionamiento del órgano del lenguaje, vinculado con aspectos paramétricos.

Corolario 1: La versión clásica del modelo de Principios y Parámetros tenía una imagen ingenua del carácter genéticamente determinado del lenguaje, dado que no consideraba la acción de la epigénesis o del efecto Baldwin.

Corolario 2: El desarrollo lógico del programa minimalista conduce a una visión más rigurosa de la relación entre genes y lenguaje, y predice deductivamente una concurrencia de genes en la filogenia y ontogenia del lenguaje.

Corolario 3: En una reconstrucción racional del programa minimalista se colige que conduce inevitablemente al giro biolinguíístico, según el cual el innatismo del lenguaje se restringe a la operación de ensamble y la recursividad sintáctica. Razón por la cual debe reconsiderarse la hipótesis tradicional del innatismo.

\section{Aspectos metodológicos}

En líneas generales, la ciencia se rige por una tríada fundamental: Problema - Teoría - Evidencia. Cada matriz disciplinaria desarrolla un modo idiosincrásico de presentar la tríada y ello se ve reflejado en los estudios de epistemologías regionales. Ahora bien, la naturaleza conceptual de la indagación se puede explicar a partir de una propuesta del filósofo Charles S. Peirce (1878) acerca de la abducción, el razonamiento creativo que nos lleva a una hipótesis original.

Sobre la base de una teoría o un framework vital dentro de una comunidad científica, se observa la realidad que suscita el interés científico. Se concibe, así, un problema científico y esto marca el comienzo de la indagación. Frente al problema, procede el razonamiento denominado abducción que conduce a una hipótesis o teoría. Es crucial, en la abducción, una desautomatización de 
la percepción, que prepara al científico para darse cuenta de algunos aspectos novedosos, inadvertidos por los investigadores insertados en el marco tradicional. A partir de la hipótesis, se deducen una serie de consecuencias que permiten la evaluación de las ideas iniciales del científico. Si las consecuencias son efectivamente observadas, merced a un razonamiento inductivo, se puede establecer la plausibilidad (no la verdad) de la hipótesis del científico.

El esquema peirciano es una buena aproximación a la tríada de la ciencia (problema - teoría - evidencia), porque establece la génesis de las ideas innovadoras y considera que la relación entre la evidencia y la teoría solo puede ser inductiva. Ninguna evidencia positiva puede probar fehacientemente una teoría (no existe la verificación absoluta), pero sí otorga ciertas credenciales a su favor. Aunque se ha tratado de determinar grados de confirmación enmarcados en una concepción cuantitativa, la confirmación de una teoría entraña procedimientos cualitativos. Por ejemplo, si de la teoría se deduce una consecuencia impensada, sumamente improbable para la comunidad científica, y, finalmente, la consecuencia se observa, ello otorga una evidencia crucial para la teoría (más de lo que pudiera brindar un nutrido conjunto de confirmaciones triviales).

Partimos en este trabajo de una metodología interna tal como es asumida en el framework generativo (Lohndal \& Narita 2009). Ello nos conduce a hacer una abstracción para definir el lenguaje mínimamente como la suma de ensamble y recursión, dejando de lado aspectos sumamente interesantes como los tocados por la pragmática linguística. Tales aspectos pueden tener enormes implicancias, pero la mirada científica debe soslayarlos por un acendrado prurito científico. Operar con restricciones metodológicas semejantes es un procedimiento típico en las ciencias naturales maduras. No obstante, ciñéndonos al lenguaje-I, en el sentido más perspicuo de la gramática generativa, efectuamos una mirada correlativa a los aspectos de la biología del cerebro en una extensión que tratará de aclarar el misterio de la relación entre genes y lenguaje.

Teniendo en cuenta que la biolinguiística no es una hipótesis sustantiva ni una teoría ni la versión actual de la gramática generativa formal, sino un programa de investigación en el sentido lakatosiano, debemos asumir que nos conduce a una suerte de giro, casi a una verdadera revolución. Esto tiene repercusiones metodológicas. Así, nuestro marco metodológico sigue el precepto enunciado por Fitch (2009: 310):

I emphasized above that the model for progress in biolinguistics will be empirical testing of theoretical predictions along the lines of physics or molecular biology.

De suerte que debemos establecer ciertos correlatos biológicos que establezcan nexos entre, por ejemplo, el descenso de la laringe o las homologías de la etología comparada con el poder de la recursividad sintáctica y la veloci- 
dad de la adquisición del lenguaje. Nuevamente, resulta ingenuo pensar que se puede hallar correlaciones muy sustantivas: por ejemplo, que la teoría de las lindes esté presente en las redes neuronales del cerebro. Así, las disquisiciones presente en ensayos como el de López García (2002) no son más que un escarceo superficial y poco revelador.

Resulta estimulante, desde la perspectiva metodológica, intentar hallar los engarces causales entre los genes candidatos y las asimetrías linguiísticas porque, de ese modo, se pueden proyectar abducciones sobre la GU y el innatismo linguiístico, en los estrictos límites que hemos considerado. El estudio del gen FOXP2 se eleva a un estatus emblemático:

While it remains an unfinished task to identify the final causal links to language impairments, the discovery and analysis of this gene [i. e. FOXP 2 ] and the genes that it regulates have served as an extremely useful example of how to unravel via genomics the complex phenotype that is human language (Li et alii 2007: 16).

\section{Exposición de resultados y validación de hipótesis}

Frente a la pregunta capital de cómo evolucionó el lenguaje, el razonamiento medular del PM implica postular una base linguiística altamente restrictiva que se configura con una sintaxis mínima (se habla, por ello, del fin de la sintaxis). El PM deriva una aproximación metodológica que subtiende una explicación de los fenómenos linguiísticos con un aparato teórico bastante parsimonioso (con la actuación de la célebre navaja de Occam) y que conduce inevitablemente a establecer la naturaleza biológica del lenguaje (el giro biolinguiístico). Como dicen Di Sciullo et alii (2010: 6), «ultimately, we want to link grammars to the brain, but at this stage we do not expect to be able to predict properties of neural organization from properties of grammar». Para decirlo de la manera más rústica posible, no hay que esperar establecer un link sustantivo entre la dependencia estructural y una red neuronal cerebral.

En la perspectiva de hallar la relación entre genes y lenguaje, la teoría más plausible apunta a establecer que un número de genes conspiran para producir las propiedades de la facultad del lenguaje en sentido estricto: la fusión o ensamble (merge) y la recursión. Es probable que la recursión ya esté presente en los demás animales, pero solo tendría con el lenguaje humano una relación homológica, no analógica.

El minimalismo no solo entraña un refinamiento del modelo de P\&P. Este modelo solo apuntalaba un correlato metafórico con las constricciones biológicas, pero el programa minimalista establece literalmente una primacía genética, lo que nos lleva a la idea del genotipo linguíístico (Lightfoot 2006). 
Las consecuencias para el innatismo son evidentes. La GU se puede entender con ayuda del efecto Baldwin, lo que dejaría a los mecanismos epigenéticos para la explicación de la maduración paramétrica. En esquema:

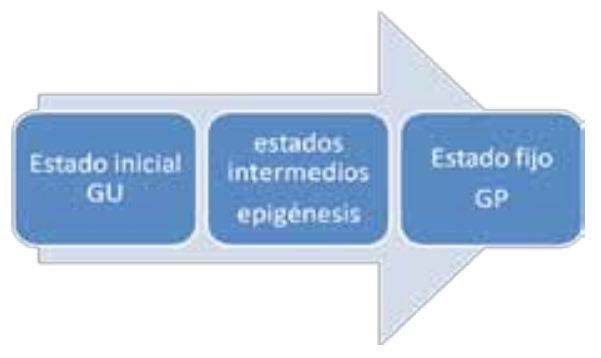

La dilucidación del estado inicial (GU) se sustenta en los nuevos principios involucrados en la evolución y desarrollo del cerebro (Striedter 2006). Una validación externa tiene que ver con el hallazgo de áreas estructuralmente no isomorfas entre el cerebro humano y el cerebro chimpancé (Enard et alii 2009).

El descubrimiento inicial del gen FOXP2 fomentó un gran entusiasmo que, poco a poco, se ha ido enfriando, dado que el mediático gen se ha encontrado en otros animales cumpliendo otras funciones no análogas, lo que implicaría apuntar los estudios hacia la relación entre genes y proteínas con el fin de obtener resultados más promisorios para la hipótesis del innatismo. Con todo, como establecen Di Sciullo et alii (2010: 14):

Classical heritability studies establish beyond a doubt that there are language components that are 'innate', that is, that have a significant genetic component, since estimates for the additive variance attributable to genes ranges between $0.4-0.6$, roughly comparable to hair color.

La evidencia de la especificidad genética en los factores linguísticos se entiende como una validación del innatismo, incluso en los términos más acendrados establecidos desde los primeros escarceos de la gramática generativa. Tanto así que la negación de esta relación solamente se podría hacer desde la nesciencia más estólida o del marasmo en la capacidad de razonar científicamente (cf. Stromswold 2005 para referencias más directas).

La aplicación de la imagenología cerebral establece el rol del área de Broca, por ejemplo, en las construcciones sintácticas, lo que analizado con prudencia, sin embargo, nos conduce a corroborar las hipótesis sobre el innatismo de la GU en la medida en que se aplica a toda la especie humana con un rango de variación muy reducido (Friederici 2009).

Asimismo, se puede tomar como una validación científica que las familias que padecen el specific language impairment (SLI) evidencian serios problemas 
en la concordancia y en el trabajo con el tiempo verbal (Wexler et alii 2004), lo que nos lleva a postular que hay una evidente relación (no sustantiva, por cierto) entre el cromosoma 19 y el factor del tiempo verbal (tense).

\section{Análisis y sistematización}

En una reseña más que laudatoria, Víctor Longa (2009) se refiere a la obra de Antonio Benítez Burraco (2009) en estos términos:

The author is well aware of the dangers a strictly reductionist perspective has meant for the biological study of organisms. ABB's own words clearly illustrate: "[...] the genetic approach to the study of language should not be understood from a strictly reductionist perspective, which considers the gene to be the final point of any analysis of language". [...] For that reason, the author contends that knowledge gained from genetic and molecular analyses should be integrated in an overall picture. [...] Consequently, according to $\mathrm{ABB}$, genes are not the main biological entities, but they strongly interact with the whole range of developmental resources and levels (cellular, neural, behavioral, environmental, and so on) of which the system is composed. Such a position concerning the role attributed to the genes is in full agreement with theoretical stances which strongly depart from Neo-Darwinian assumptions; in fact, in several passages of the book, ABB suggests that his proposal fits in well with Developmental Systems Theory (cf. p. 363, among others), and with the view sustained by MP as well. Thus, for ABB the genome cannot be conceived of as an encapsulated entity.

Un enfoque reduccionista radical es científicamente inviable y teóricamente implausible en la medida en que propondría un esquema totalmente falso y fallido:

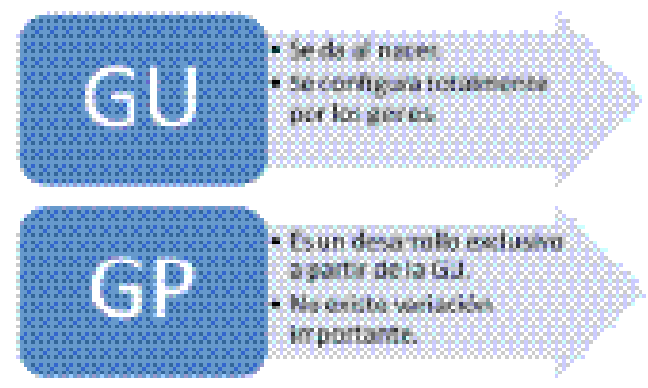

Este enfoque haría predicciones absurdas como las que un niño peruano al nacer ya podría construir oraciones en castellano, por ejemplo, y, por ello, tiene que ser desechado sobre la base de consideraciones lógicas y factuales. 
Resulta evidente considerar que los genes por sí solos no aseguran el lenguaje (la GU no permite la construcción de mensajes): hay aspectos de maduración y de epigénesis involucrados en la parametrización, lo que, finalmente, conduce a desarrollar una gramática particular (como la del inglés, del castellano, del quechua, del euskera o del awajún), el mecanismo necesario para que la numeración (en el sentido técnico del programa minimalista) se pueda emplear en la construcción práctica de mensajes linguiísticos. Como argumentan con convicción Lorenzo \& Longa (2003), el programa minimalista entraña también una reducción de la acción endógena de los genes.

Una hipótesis fuerte de determinación absoluta entre genes y lenguaje, sencillamente, no corresponde al plano de la discusión científica; ni siquiera pertenece a lo que se puede denominar teoría linguíística popular (más embelesada en la historia de las palabras).

En lo referente al tópico fundamental de genes y lenguaje, el aporte de Benítez Burraco (2009) es esencial y nos servirá para la sistematización siguiente:

\begin{tabular}{|c|l|l|}
\hline $\begin{array}{c}\text { Denomina- } \\
\text { ción del gen }\end{array}$ & \multicolumn{1}{|c|}{ Sintomatología lingüística } & Posible función lingüística \\
\hline FOXP2 & $\begin{array}{l}\text { Variada, la que más destaca es la } \\
\text { reducida comprensión morfosin- } \\
\text { táctica. }\end{array}$ & $\begin{array}{l}\text { Aspectos de concordancia y de } \\
\text { fusión (merge). }\end{array}$ \\
\hline SLC6A8 & $\begin{array}{l}\text { Problemas articulatorios y lin- } \\
\text { guísticos. }\end{array}$ & Producción del mensaje. \\
\hline SUOX & Desarrollo mínimo del lenguaje. & Aspectos sintácticos y semánticos. \\
\hline PAH & Falta de fluidez fonémica. & Memoria verbal. \\
\hline GCDH & $\begin{array}{l}\text { Merma evidente en la expresión } \\
\text { verbal. }\end{array}$ & Producción del lenguaje. \\
\hline Locus SLI & Trastorno específico del lenguaje. & $\begin{array}{l}\text { Aspectos del tiempo (tense) y de } \\
\text { la concordancia. }\end{array}$ \\
\hline DYX1C1 & Dislexia. & Transferencia fonológica. \\
\hline HD (HTT) & $\begin{array}{l}\text { Anomalías serias en la nomina- } \\
\text { ción, la definición y la interpreta- } \\
\text { ción de significados. }\end{array}$ & Aspectos léxico-semánticos. \\
\hline SRPX2 & $\begin{array}{l}\text { Trastorno en la comprensión ver- } \\
\text { bal. }\end{array}$ & $\begin{array}{l}\text { Aspectos de la comprensión lin- } \\
\text { guística. }\end{array}$ \\
\hline ALDH5A1 & $\begin{array}{l}\text { Desarrollo insuficiente de las ca- } \\
\text { pacidades linguísticas. }\end{array}$ & $\begin{array}{l}\text { Dispositivo para adquirir el len- } \\
\text { guaje (DAL). }\end{array}$ \\
\hline MAPT & $\begin{array}{l}\text { Disminución de la producción lin- } \\
\text { guística general. }\end{array}$ & $\begin{array}{l}\text { Dispositivo para adquirir el len- } \\
\text { guaje (DAL). }\end{array}$ \\
\hline NJD & Problemas de locución. & Aspectos fonológicos y articulatorios. \\
\hline
\end{tabular}


En rigor, el estudio de Benítez Burraco propone una lista de más de cien genes involucrados en aspectos del lenguaje, pero no se trata de una lista sólida en la medida en que muchos genes van más allá de aspectos linguíísticos y rozan lo cognitivo. En rigor, varios de ellos tienen un efecto concurrente en el plano linguíístico y otros dependen de diversos elementos de la cognición. Por ejemplo, si un gen está involucrado con un problema de regresión de una capacidad linguiística (primero el individuo desarrolla normalmente la capacidad linguística y, luego, la olvida) se puede conjeturar razonablemente que el problema va más allá de la esfera del lenguaje y se abre una disyuntiva científica: o abandonamos parcialmente la tesis de la modularidad o simplemente constatamos ciertos efectos concomitantes que no invalidan la tesis de la modularidad.

\section{Discusión y conclusiones}

Dado que el genoma es un programa con cierta flexibilidad, se ha postulado recientemente que el desarrollo de lenguaje involucraría aspectos de la epigénesis. La epigénesis implica una estrecha interacción entre la información del programa de desarrollo y la información que se asimila del entorno. De acuerdo con este marco explicatorio, la estimulación ambiental dejaría de ser considerada como un simple efecto desencadenante y adquiriría una fuerza especial en la motorización del órgano del lenguaje.

Es sabido que la epigénesis actúa sobre la célula, lo que se proyecta en la posible interacción entre genes y células (Waddington 1957). En la mirada de Changeux (2002), se postula inclusive una epigénesis neuronal que consiste en la formación de billones de sinapsis al margen del control absoluto de los genes, y, es más, apuntarían a un cierto efecto del entorno en los genes (lo que se vería en el proceso de lo que se denomina neurulación).

En virtud de lo anterior, Tomasello (2001) inclusive pone de relieve el trayecto cultural en la configuración simbólica del lenguaje, razón por la cual refuta tajantemente la hipótesis del instinto del lenguaje. Probablemente, esa confutación del instinto del lenguaje se pueda argumentar mejor desde los nuevos puentes entre evolución y desarrollo construidos por la biología evolutiva del desarrollo (evolutionary developmental biology o evo devo). En trabajos como los de Bates (1999), se dilucida con mayor sagacidad científica la interacción epigenética entre genes y entorno externo que va más allá del mero anatema de Tomasello. Ciertamente, no se puede negar que el mecanismo epigenético juegue un rol importante en el desarrollo de los circuitos neuronales que subyacen en el funcionamiento del lenguaje.

Todo lo anterior resulta del hecho de que se utiliza una definición más o menos lata del lenguaje. Por ello, en la presente investigación, hemos operado con una parsimonia definitoria para reducir el lenguaje a dos criterios 
operativos científicamente: fusión o ensamble (merge) y recursividad. Solo así podríamos salir de la borrasca de la polémica meramente terminológica. Es evidente que cuando Tomasello dice que el lenguaje no es un instinto está pensando en propiedades del lenguaje que no están presentes en el dictum célebre de Pinker. Se trataría de una polémica bizantina muy alejada de un verdadero espíritu científico.

Un detalle importante para tener una mirada más circunspecta al respecto. El color de ojos es genético y depende de los padres en una determinación muy clara. Sin embargo, ello no ocurre con el lenguaje: el niño no hereda la lengua de la madre, sino que desarrolla la lengua de sus cuidadores, sean sus padres o no. La expresión "lengua materna" es claramente metafórica. En cambio, el niño heredará el color de ojos así no crezca con sus progenitores.

Luego del entusiasmo inicial (bastante mediático) sobre el gen FOXP2, las aguas se tranquilizaron porque se reconoció que había más cosas que aclarar en torno a ese popular gen. Tanto Bosman et alii (2004) y Corbalis (2004) nos dan una mirada más circunspecta y en el futuro tendremos análisis más prolijos y concluyentes.

El programa minimalista se puede considerar o bien como un refinamiento del modelo de P\&P o, como apunta Antonio Benítez Burraco, una ruptura epistemológica con consecuencias ontológicas más que metodológicas. Lo último se vería reforzado si se impone una nueva concepción de lo innato que restrinja ciertas interpretaciones maximalistas. No obstante, y sin tratar de romper el nudo gordiano a la manera clásica, postulamos que lo innato del lenguaje se puede defender con ayuda del recurso al efecto Baldwin y con la definición mínima del lenguaje que nos parece de una necesidad científica evidente.

Con respecto al vínculo entre genes y lenguaje, se impone, finalmente, la visión moderada de Benítez Burraco (2006: 59):

Una conclusión inmediata de las evidencias presentadas en este trabajo consiste, desde luego, en la circunstancia de que nunca será posible encontrar genes responsables de la flexión nominal o que regulen el procesamiento de las oraciones con cláusulas embebidas, como demandaba ingenuamente una aproximación simplista a la dilucidación del problema de las bases genéticas del lenguaje. En cambio, sí parecen existir genes que se ajustan en gran medida a la definición de "gen del lenguaje» propuesta por Pinker [(2001), pp. 352-53], al menos si se interpreta de forma laxa, puesto que se dispone actualmente de algunos datos, ciertamente fragmentarios, acerca de algunos de los genes que integrarían el programa encargado del desarrollo y el funcionamiento de determinadas regiones cerebrales, estructuras histológicas, conjuntos neuronales o procesos a nivel citológico (capaces, además, de integrar la información que llega del exterior), relacionados con el lenguaje. 
Las discusiones biolinguiísticas suelen hacer una paráfrasis del célebre aserto de Dobzhansky: Nada tiene sentido en el lenguaje si no se enmarca en el contexto de la biología de la gramática. Se trata de una paráfrasis efectista y que causa un impacto tanto en un biólogo como en un linguiista. Sin embargo a partir de ese giro parafrástico se derivan conclusiones que difícilmente se resolverán en poco tiempo (como sugiere prudentemente Jackendoff): La biolinguística es una ciencia joven (un proyecto, al decir de Fitch), pero, indudablemente, será muy longeva.

\section{Referencias bibliográficas}

BALDWIN, J. M. (1896). A new factor in evolution. American Naturalist, 30; pp. 441-451. BAHRICK, L. E. (1988). Intermodal Learning in Infancy: Learning on the Basis of Two Kinds of Invariant Relations in Audible and Visible Events. Child Development, 59; pp. 197-209.

BARKOVICH, A. J. et alii (2001). Callosal agenesis with cist. A better understanding and a new classification. Neurology, 56; pp. 220-227.

BATES, E. (1999). Plasticity, localization and language development. In Sarah H. Broman \& Jack M. Fletcher (eds.) The Changing Nervous System: Neurobehavioral Consequences of Early Brain Disorders; pp. 214-253. New York: Oxford University Press.

BENÍTEZ BURRACO, A. (2006). Genes y lenguaje. Teorema XXVI/1; pp. 37-71.

BENÍTEZ BURRACO, A. (2009). Genes y lenguaje. Aspectos ontogenéticos, filogenéticos y cognitivos. Barcelona: Editorial Reverté.

BOECKX, C. \& GROHMANN, K. (2007). The Biolinguistics Manifesto. Biolinguistics 1; pp. 1-8.

BOSMAN, C. et alii (2004). FoxP2 and the language working-memory system. Trends in Cognitive Science 8; pp. 251-252.

CALVIN, W. \& BICKERTON, D. (2000). Lingua ex Machina. Cambridge MA: The MIT Press.

CARROLL, S. (2005). Endles Forms Most Beautiful: The New Science of Evo Devo and the Making of the Animal Kingdom. New York: W. W. Norton.

CHANGEUX, J.P. (2002). L'Homme de vérité. París: Odile Jacob.

CHOMSKY, N. (1995). The Minimalist Program. Cambridge MA: MIT Press.

CHOMSKY, N. (2002). On Nature and Language. Cambridge: CUP.

CHOMSKY, N. (2005). Three factors in language design. Linguistic Inquiry 36; pp. 1-22.

CONTI-RAMSDEM, G., BOTTING, N. \& FARAGHER, B. (2001). Psycholinguistic Markers for Specific Language Impairment (SLI). Journal of Child Psychology and Psyquiatry, 42, 6; pp.741-748.

CORBALIS, M. (2004). FoxP2 and the mirror system. Trends in Cognitive Sciences 8; pp. 95-96.

CUTLER, A. et alii (1983). A Language-Specific Comprehension Strategy. Nature, 304; pp. 159-160.

DEACON, T. (1997). The symbolic Species: The coevolution of Language and the Brain.New York: W.W. Norton.

ENARD, W. et alii (2009). A humanized version of Foxp2 affects cortico-basal ganglia circuits in mice. Cell 137; pp. 961-971. 
EVERETT, D. (2005). Cultural constraints on grammar and cognition in Pirahã. Current Anthropology 46; pp. 621-646.

FITCH W. T. et alii (2005). The evolution of the language faculty: Clarifications and implications. Cognition 97; pp. 179-210.

FITCH, W. T. (2009). Prolegomena to a Future Science of Biolinguistics. Biolinguistics 3.4; pp. 283-320.

FODOR, J. A. (2008). LOT 2: The Language of Thought Revisited. Oxford: Clarendon Press.

FRIEDERICI, A. (2009). The brain differentiates hierarchical and probabilistic grammars. In Piatelli- Palmarini, M., Uriagereka, J., \& Salaburu, P. (eds.) 2009. Of Minds and Language: A Dialogue with Noam Chomsky in the Basque Country. Oxford: Oxford University Press.

GIVÓN, T. (2002). Bio-Linguistics: The Santa Barbara Lectures. Amsterdam: John Benjamins. GOPNIK, M. (ed.) (1997). The inheritance and innateness of grammars. Oxford: Oxford University Press.

HAUSER, M. et alii (2002). The faculty of language: what is it, who has it, and how did it evolve? Science 298; pp. 1569-1579.

HJELMSLEV, L. (1943). Prolegómenos a una teoría del lenguaje. Madrid: Gredos (1971).

HURFORD, James R. 2007. The Origins of Meaning (Language in the Light of Evolution). Oxford: Oxford University Press.

JACKENDOFF, R. (2002). Foundations of Language. New York: Oxford University Press.

JACKENDOFF, R. \& PINKER, S. (2005). The nature of the language faculty and its implications for evolution of language. Cognition 97; pp. 211-225.

JENKINS, Lyle. 2000. Biolinguistics: Exploring the Biology of Language. Cambridge: CUP.

JENKINS, Lyle (ed.). 2004. Variation and Universals in Biolinguistics (North-Holland Linguistic Series: Linguistic Variations 62). Amsterdam: Elsevier.

KIRSCHNER, M. \& GERHART, J. (2005). The Plausibility of Life: Resolving Darwin's Dilemma. New Haven: Yale University Press.

KNÖRNSCHILD, M et alii (2009). Complex vocal imitation during ontogeny in a bat. Biology Letters, 5; pp. 1-4.

LENNEBERG, E. (1967). Biological Foundations of Language. New York: Wiley.

LI, G. et alii (2007). Accelerated FoxP2 evolution in echolocating bats. Public Library of Science One 2 e 900.

LIGHTFOOT, D. (2006). How New Languages Emerge. Cambridge: CUP.

LIEBERMAN, Ph. (2006). Toward an Evolutionary Biology of Language. Cambridge MA: Harvard University Press.

LOHNDAL, T. and NARITA, H. (2009). Internalism as Methodology. Biolinguistics, 3.4, pp. 321-331.

LONGA, V. \& LORENZO, G. (2008). What about a (really) minimalist theory of language acquisition? Linguistics 46 (3); pp. 541-570.

LONGA, V. (2009) Everything You Wanted to Know About the Genetics of Language (and Beyond). Review in Biolinguistics 3.4; pp.412-419.

LÓPEZ GARCÍA, A. (2002). Fundamentos genéticos del lenguaje. Madrid: Cátedra.

LORENZO, G. \& LONGA, V. (2003). Minimizing the genes for grammar. The minimalist program as a biological framework for the study of language. Lingua, 113; pp. 643-657. 
MARCUS, G. (2004)The Birth of the Mind. How a Tiny Number of Genes Createsthe Complexities of Human Thought, New York: Basic Books.

MEHLER, J. \& DUPOUX, E. (1990). Naître Humain. París: Odile Jacob.

PIAGET, J.; CHOMSKY, N. et alii (1983). Teorías del lenguaje / Teorías del aprendizaje: el debate entre Jean Piaget y Noam Chomsky. Barcelona: Crítica.

PINKER, S. (1994). The Language Instinct. New York: William Morrow and Company, Inc.

PINKER, S. \& JACKENDOFF, R. (2005). The faculty of language: what's special about it? Cognition 95; pp. 201-236.

PEIRCE, Ch. S. (1878): Deduction, Induction and Hypothesis. Popular Science Monthly, XIII; pp. 470-482.

POEPPEL, D. \& EMBICK, D. (2005). Defining the relation between linguistics and neuroscience. In Anne Cutler (ed.). Twenty-First Century Psycholinguistics: Four Cornerstones, pp. 103-120. Mahwah, NJ: Lawrence Erlbaum Associates.

POLLOCK, J-Y. (1989). Verb Movement, Universal Grammar, and the Structure of IP. Linguistic Inquiry, 20, 3, Summer; pp. 365-424.

SAHIN, N. et alli (2009). Sequential Processing of lexical, grammatical and phonological information writen Broca's Area. Science, vol. 326,16 october 2009; pp. 445-449.

SMITH, N. \& TSIMPLI, I.-M. (1995). The Mind of a Savant. Oxford: Blackwell.

SMITH, N. \& LAW, A. (2007). Twangling instruments: Is parametric variation definitional oh human language? UCL Working Papers in Linguistics 19; pp. 1-28.

STRIEDTER, G. (2006). Precis of Principles of Brain Evolution. Behavioral and Brain Sciences 29 (1); pp. 1-12.

STROMSWOLD, K. (2005). Genetic specificity of linguistic heritability. In Anne Cutler (ed.) Twenty-First Century Psycholinguistics: Four Cornerstones; pp. 103-120. Mahwah, NJ: Lawrence Erlbaum Associates.

TOMASELLO, M. (2001). Cultural transmission: A view from chimpanzees and human infants. Journal of Cross-Cultural Psychology 32, 135-146.

WADDINGTON, C. (1957). The Strategy of the Genes: A Discussion of Some Aspects of Theoretical Biology. London: Allen and Unwin.

WEXLER, K. et alii (2004). Verbal syntax and morphology in Dutch normal and SLI children: How developmental data can play an important role in morphological theory. Syntax 7; pp. 148-198. 